\title{
FAKTOR-FAKTOR YANG BERHUBUNGAN DENGAN TINGKAT ADOPSI PETANI PADA TEKNOLOGI BUDIDAYA PADI SAWAH SISTEM LEGOWO DI KELURAHAN DUSUN BESAR KECAMATAN GADING CEMPAKA KOTA BENGKULU
}

\author{
Satria Putra Utama ${ }^{1}$ \\ Indra Cahyadinata ${ }^{1}$ \\ Rahmad Junaria ${ }^{2}$ \\ ${ }^{1}$ Staf Pengajar Jurusan Sosial Ekonomi Pertanian Fak. Pertanian UNIB \\ ${ }^{2}$ Alumni Jurusan Sosial Ekonomi Pertanian Fak. Pertanian UNIB
}

\begin{abstract}
The study aimed at identification the factors that connected with the level of farmer's adoption toward the rice field's technology in legowo system in Dusun Besar, Gading Cempaka subdistrict Bengkulu town were level education, age, the wider of farm, experience, motivation, activity of the farmer in counseling, farmer's conception about legowo system and farmer's cosmopolittness. The study was conducted in Dusun Besar, Gading Cempaka subdistrict Bengkulu town. Total samples were 40 farmers and data collection was observation method, documentation method and method of questionaire. Data were analyzed using Statistic non parametric that is correlation test of rank spearman. The result of this research showed that the level of farmer's adoption toward technology in legowo system in Kelurahan Dusun Besar, Gading Cempaka subdistrict, Bengkulu Town were high. And also there were correlation between the factor of the level education, motivation, activity of the farmer in counseling, farmer's conception about legowo system with the level of farmer adoption toward rice field's technology in legowo system. In otherwise, there was no correlation between age, the wider of farm, experience, and farmer's cosmopolittness with the level farmer adaption toward the rice field's technology in legowo system.
\end{abstract}

Key words:

\section{PENDAHULUAN}

Usaha peningkatan produksi pertanian salah satunya diwujudkan dengan pemberian pengetahuan dan keterampilan penggunaan teknologi (inovasi) pertanian modern, dengan harapan agar petani bersedia merubah pola dan struktur pertanian yang tradisional. Teknologi pertanian modern telah banyak diadopsi oleh petani terutama sejak dilaksanakannya Pembangunan Lima Tahun (Pelita) pertama mulai tahun 1969, yang dalam pelaksanaannya diantaranya berisikan pembangunan pertanian melalui introduksi pertanian modern. 
Adanya introduksi pertanian modern menyebabkan banyaknya perubahan yang terjadi terutama di daerah pedesaan. Hal ini sesuai dengan apa yang termuat dalam GBHN 1993 bahwa pembangunan pertanian pada hakekatnya merupakan usaha meningkatkan kegiatan-kegiatan dibidang pertanian dalam upaya pemanfaatan kekayaan sumber daya alam secara lestari dan berkelanjutan, serta untuk menciptakan perubahan sosial.

Bengkulu Regional Development Project (BRDP) adalah salah satu program untuk mengentaskan kemiskinan serta menunjang pengembangan ekonomi pedesaan di Bengkulu. BRDP merupakan proyek yang didanai oleh Bank Dunia, salah satu kegiatan proyek adalah adopsi teknologi pertanian dengan melakukan uji coba paket teknologi yang sesuai dengan potensi desa sasaran. Dalam pelaksanaannya BRDP bekerja sama dengan Balai Pengkajian Teknologi Pertanian (BPTP).

Suminar (1989) mengatakan bahwa gencarnya usaha pembaharuan pola bertani melalui penerapan cara dan alat lebih modern, tidak akan menjamin adanya perubahan yang mendasar dari perilaku masyarakat petani didalam mengelola usahataninya. Hal ini disebabkan karena mentalitas mereka belum siap untuk segera meninggalkan keseluruhan pola-pola lama yang memang sudah mapan untuk ukuran keberhasilan mereka. Kenyataan seperti ini lebih banyak diwujudkan dengan berbagai penolakan terhadap inovasi baru yang diperkenalkan pada mereka. Alasannya karena inovasi tersebut dianggap telah bertentangan dengan adat dan kebiasaannya selama ini. Kasus seperti ini memberikan lebih banyak informasi pada kita, bahwa yang pertamatama harus dirubah adalah mentalitas petani itu sendiri agar mereka lebih luwes menerima pembaharuan. Yang menjadi pemikiran kita adalah faktor-faktor apakah yang sekiranya dapat dijadikan wahana didalam proses modernisasi mentalitas petani. 
Redfield (1982) mengungkapkan bahwa pandangan hidup suatu kaum tani tertentu akan mempunyai kesamaan-kesamaan tertentu dengan kaum tani lainnya, akan tetapi tidak senantiasa pada titik-titik kesamaan yang sama. Artinya strategi yang dikembangkan oleh petani itu pada umumnya sama, namun strategi yang dikembangkan tidak senantiasa sama pada daerah-daerah tertentu. Hal itu dibuktikan oleh petani di Kelurahan Dusun Besar Kecamatan Gading Cempaka Kota Bengkulu yang telah mengadopsi usaha tani padi sawah sistem legowo sebagai strategi mereka untuk meningkatkan pendapatannya.

Faktor-faktor yang menghambat atau memperlancar usaha adopsi teknologi lebih banyak dipengaruhi oleh situasi dan kondisi dalam diri petani itu sendiri. Dalam penelitian ini dicoba untuk mengidentifikasi berbagai faktor yang sekiranya memiliki hubungan terhadap usaha adopsi teknologi budidaya padi sawah sistem legowo. Faktorfaktor tersebut adalah tingkat pendidikan formal, umur, luas lahan, pengalaman berusahatani padi, motivasi petani, aktifitas petani dalam penyuluhan, persepsi petani mengenai teknologi usahatani padi sawah sistem legowo serta kosmopolitness petani. Penelitian ini dimaksudkan untuk mempelajari hubungan tingkat pendidikan formal, umur, luas lahan, pengalaman berusahatani padi, motivasi petani, aktivitas petani dalam penyuluhan, persepsi petani mengenai teknologi budidaya padi sawah sistem legowo dan kosmopolitness petani terhadap tingkat adopsi petani pada teknologi budidaya padi sawah sistem legowo.

\section{METODOLOGI PENELITIAN}

Penentuan lokasi dalam penelitian ini dilakukan secara purposive ( sengaja ) yaitu di Kelurahan Dusun Besar Kecamatan Gading Cempaka Kota Bengkulu. Dengan pertimbangan daerah penelitian tersebut $100 \%$ petani telah menerapkan sistem tanam legowo dan hingga kini, petani di Kelurahan Dusun Besar masih tetap menerapkan 
teknologi legowo dalam budidaya padi sawah mereka. Pengambilan sampel petani padi sawah sistem legowo di Kelurahan Dusun Besar Kecamatan Gading Cempaka Kota Bengkulu dilakukan dengan metode Random Sampling (Nazir,1988), jumlah sampel petani ditetapkan sebanyak 20 orang petani dari 40 orang petani.

Analisis data yang digunakan untuk mengetahui hubungan antara variabelveriabel bebas yang diteliti terhadap tingkat adopsi adalah analisis Statistik Non Parametrik, yaitu uji korelasi Rank Spearman (rs).

Untuk menghitung koefisien korelasi (rs) menurut Siegel (1998) digunakan

rumus sebagai berikut: $\quad r s=1-\frac{6 \sum_{i-1}^{n} d i^{2}}{N^{3}-N}$

dimana :

rs : Koefisien korelasi rank spearman

di : Selisih antara variabel X dengan veriebel Y pada responden ke-i

i : Nomor responden

$\mathrm{N} \quad$ : Jumlah responden

6 : Konstanta

jika terjadi angka sama, maka rs yang digunakan adalah rs dengan menggunakan faktor koreksi, dengan rumus sebagai berikut:

$$
\begin{aligned}
& \boldsymbol{T x}=\frac{\boldsymbol{t}_{x}{ }^{3}-\boldsymbol{t}_{x}}{12} \\
& \boldsymbol{T y}=\frac{\boldsymbol{t}_{y}{ }^{3}-\boldsymbol{t}_{y}}{12} \\
& \sum x^{2}=\frac{n^{3}-n}{12}-\sum T x \\
& \sum y^{2}=\frac{n^{3}-n}{12}-\sum T y
\end{aligned}
$$


Dengan faktor koreksi di atas, maka perhitungan koefisien korelasi Rank Spearman (rs) adalah sebagai berikut :

$$
r s=\frac{\sum x^{2}+\sum y^{2}-\sum d i^{2}}{2 \sqrt{\sum x^{2} \sum y^{2}}}
$$

Dimana :

Tx : Koreksi angka sama variabel $\mathrm{X}$ variabel Y

tx : Banyaknya angka sama variabel $\mathrm{X}$

ty : Banyaknya angka sama variabel $\mathrm{Y}$
Ty : Koreksi angka sama

$\sum x^{2}:$ Faktor koreksi variabel $\mathrm{X}$

$\sum y^{2}:$ Faktor koreksi variabel Y

Untuk menguji signifikan digunakan uji t dengan rumus:

$$
\mathrm{t}_{\text {hitung }}=\mathrm{rs} \sqrt{\frac{N-2}{1-r s^{2}}}
$$

maka t hitung (observasi) dibanding dengan $\mathrm{t}$ tabel dengan arah dua sisi. Tingkat signifikan yang digunakan 95\% ( $\alpha=5 \%)$, dengan kaidah pengujian sebagai berikut:

- $\quad$ Jika $\mathrm{t}$ hitung $\geq \mathrm{t}$ tabel atau - $\mathrm{t}$ hitung $\leq$ - tabel, maka Ho ditolak Hi diterima.

- Jika -t hitung >-t tabel atau t hitung < t tabel, maka Ho diterima Hi ditolak.

\section{HASIL DAN PEMBAHASAN}

Karakteristik petani responden yang diamati dalam penelitian ini meliputi pendidikan formal, umur petani, luas lahan, pengalaman berusahatani padi, motivasi petani, aktifitas petani mengikuti penyuluhan pertanian, persepsi petani mengenai teknologi budidaya padi sawah sistem legowo, kosmopolitnes petani dan adopsi teknologi legowo.

Untuk mengetahui ada atau tidaknya hubungan antara variabel $(\mathrm{X})$ seperti tingkat pendidikan formal (X1), umur (X2), luas lahan (X3), pengalaman berusahatani 
padi (X4), motivasi petani (X5), aktivitas petani dalam penyuluhan pertanian (X6), persepsi petani mengenai teknologi legowo(X7), dan kosmopolitnes petani (X8) terhadap adopsi teknologi legowo (Y), maka digunakan analisis statistik non parametrik, yaitu uji korelasi Rank Spearman (rs). Hasil analisis dapat dilihat pada tabel Tabel 12. Hasil Analisis Koefisien Korelasi Rank Spearman (rs)

\begin{tabular}{|c|c|c|c|c|}
\hline No & Variabel Dugaan & rho (rs) & $\begin{array}{l}\text { Sig.(2- } \\
\text { tailed) }\end{array}$ & $\begin{array}{l}\text { Taraf } \\
\text { Nyata } \\
(\alpha / 2)\end{array}$ \\
\hline & Tingkat Pendidikan & & & \\
\hline 1 & Formal (X1) & $0,494 * *$ & 0,001 & 0,025 \\
\hline 2 & Umur (X2) & $-0,203$ & 0,209 & 0,025 \\
\hline \multirow[t]{3}{*}{3} & Luas Lahan (X3) & $-0,047$ & 0,774 & 0,025 \\
\hline & Pengalaman & & & \\
\hline & Berusahatani Padi & & & \\
\hline 4 & $(\mathrm{X} 4)$ & 0,056 & 0,731 & 0,025 \\
\hline \multirow[t]{3}{*}{5} & Motivasi Petani (X5) & $0,774 * *$ & 0,000 & 0,025 \\
\hline & Aktivitas Petani & & & \\
\hline & dalam Penyuluhan & & & \\
\hline \multirow[t]{3}{*}{6} & Pertanian (X6) & $0,961 * *$ & 0,000 & 0,025 \\
\hline & Persepsi Petani & & & \\
\hline & Mengenai Teknologi & & & \\
\hline \multirow[t]{2}{*}{7} & Legowo (X7) & $0,914 * *$ & 0,000 & 0,025 \\
\hline & Kosmopolitnes & & & \\
\hline 8 & Petani (X8) & 0,22 & 0,894 & 0,025 \\
\hline
\end{tabular}

Sumber : Data Primer Diolah, 2007 (Lampiran )

Keterangan :

$\mathrm{X} 1$ = Tingkat Pendidikan Formal

$\mathrm{X} 2=\mathrm{Umur}$

X3 = Luas Lahan

X4 = Pengalaman Berusahatani Padi 
X5 = Motivasi Petani

X6 = Aktivitas Petani dalam Penyuluhan Pertanian

X7 = Persepsi Petani Mengenai Teknologi Legowo

X8 $=$ Kosmopolitnes Petani

Y = Tingkat Adopsi Petani pada Teknologi Budidaya Padi Sawah Sistem Legowo

\section{Tingkat Pendidikan Formal}

Hasil analisis Koefisien Korelasi Rank Spearman antara variabel tingkat pendidikan formal dan tingkat adopsi petani pada teknologi budidaya padi sawah sistem legowo sebesar 0,494 dengan probabilitas untuk uji dua pihak sebesar 0,001. Karena nilai probabilitas ini lebih kecil dari taraf nyata maka disimpulkan untuk menolak hipotesis nol, berarti terdapat hubungan yang nyata antara variabel tingkat pendidikan formal dengan tingkat adopsi petani pada teknologi budidaya padi sawah sistem legowo. Dan ini signifikan pada taraf kepercayaan $95 \%$.

Kenyataan dilapangan terlihat bahwa tingginya tingkat pendidikan petani akan membuat mereka semakin mengerti tentang teknologi budidaya padi sawah sistem legowo serta penerapannya dengan baik.

Hal ini sesuai dengan pendapat Mardikanto (1993) bahwa pendidikan tinggi akan Berhubungan terhadap tingkat pengetahuan dan keterampilan petani, dimana petani akan berusaha untuk memanfaatkan setiap kesempatan yang dapat memajukan usahataninya. Selain itu beliau juga menjelaskan bahwa semakin tinggi tingkat pendidikan akan menyebabkan petani lebih responsif terhadap adopsi teknologi. Senada dengan pendapat Soekartawi (1996) yang menjelaskan bahwa pendidikan merupakan faktor penentu tingkat adopsi teknologi, pendidikan yang rendah akan menjadi kendala dalam proses adopsi teknologi baru. Hasil penelitian ini tidak sesuai dengan pendapat Juita (2005) yang menjelaskan bahwa tingkat pendidikan formal tidak berhubungan 
nyata dengan tingkat adopsi teknologi PTT. Dijelaskan bahwa hal ini disebabkan karena untuk menerapkan suatu teknologi dalam usahataninya, petani tidak harus memilki tingkat pendidikan formal yang tinggi. Petani tentunya memiliki keterampilan dan pengetahuan yang berbeda, dimana tidak semua petani berpendidikan tinggi memiliki keterampilan dan pengetahuan yang lebih tinggi dibandingkan petani yang tingkat pendidikannya rendah.

\section{Umur}

Hasil analisis Koefisien Korelasi Rank Spearman antara variabel umur dan tingkat adopsi petani pada teknologi budidaya padi sawah sistem legowo sebesar -0,203 dengan probabilitas untuk uji dua pihak sebesar 0,209. Karena nilai probabilitas ini lebih besar dari taraf nyata maka disimpulkan untuk menerima hipotesis nol, berarti tidak terdapat hubungan yang nyata antara variabel umur dengan tingkat adopsi petani pada teknologi budidaya padi sawah sistem legowo. Dan ini tidak signifikan pada taraf kepercayaan $95 \%$. Tidak berhubungan nyata antara umur dengan tingkat adopsi petani pada teknologi budidaya padi sawah sistem legowo karena adopsi teknologi legowo dapat diterapkan oleh siapa saja tanpa membedakan umur. Dan mayoritas responden dalam penelitian ini berada pada usia produktif yaitu rata-rata 40,13 tahun.

Hasil penelitian ini sejalan dengan hasil penelitian Kusai (1997) yang menjelaskan bahwa variabel umur bukanlah variabel yang menentukan tingkat adopsi teknologi oleh petani ikan. Dijelaskan bahwa sebagian besar petani ikan telah cukup lama melakukan usaha budidaya ikan sehingga memiliki waktu yang cukup lama untuk meningkatkan penerapan paket teknologi yang dianjurkan melalui proses difusi

\section{Luas Lahan}

Hasil analisis Koefisien Korelasi Rank Spearman antara variabel luas lahan dan tingkat adopsi petani pada teknologi budidaya padi sawah sistem legowo sebesar - 
0,047 dengan probabilitas untuk uji dua pihak sebesar 0,774 . Karena nilai probabilitas ini lebih besar dari taraf nyata maka disimpulkan untuk menerima hipotesis nol, berarti tidak terdapat hubungan yang nyata antara variabel luas lahan dengan tingkat adopsi petani pada teknologi budidaya padi sawah sistem legowo. Dan ini tidak signifikan pada taraf kepercayaan $95 \%$. Kenyataan dilapangan bahwa semakin luas lahan yang dimiliki petani maka akan cenderung semakin rendah penerapkan teknologi legowo pada usahataninya.

Sebaliknya, petani yang memiliki lahan yang sempit, akan semakin mudah untuk menerapkan teknologi legowo yang sesungguhnya. Hasil penelitian ini sesuai dengan pendapat Sastrawan (2000) yang menjelaskan bahwa petani dengan lahan yang luas belum tentu tingkat adopsinya tinggi dan yang terjadi adalah sebaliknya, karena petani dihantui rasa takut akan terjadinya kegagalan yang berarti malapetaka bagi petani dan keluarganya. Namun hasil penelitian ini tidak sesuai dengan pendapat Juita (2005) yang menyatakan bahwa ada hubungan yang nyata antara luas lahan dengan tingkat adopsi teknologi PTT. Dijelaskan bahwa petani didaerah penelitian mempunyai anggapan bahwa penerapan teknologi akan efisien apabila diterapkan pada lahan yang luas.

\section{Pengalaman Berusahatani Padi}

Hasil analisis Koefisien Korelasi Rank Spearman antara variabel pengalaman berusahatani padi dan tingkat adopsi petani pada teknologi budidaya padi sawah sistem legowo sebesar 0,056 dengan probabilitas untuk uji dua pihak sebesar 0,731. Karena nilai probabilitas ini lebih besar dari taraf nyata maka disimpulkan untuk menerima hipotesis nol, berarti tidak terdapat hubungan yang nyata antara variabel pengalaman berusahatani padi dengan tingkat adopsi petani pada teknologi budidaya padi sawah sistem legowo. Kerena ini tidak signifikan pada taraf kepercayaan $95 \%$. Kerena 
kegiatan usahatani padi dilakukan secara turun temurun, sehingga petani sudah mempunyai konsep atau cara tersendiri dalam berusahatani. Sedangkan teknologi legowo adalah teknologi baru, sehingga petani cenderung tidak langsung menerapkan. Meskipun menerapkan, hanya sebagian dari komponen teknologi legowo yang umum petani gunakan. Hal tersebut sejalan dengan hasil penelitian Mulyani (2001) yang menjelaskan bahwa pengalaman berusahatani tidak berhubungan nyata dengan tingkat adopsi teknologi, namun ada kemungkinan bahwa tingkat adopsi teknologi ditentukan oleh banyaknya informasi dan pengetahuan tentang teknologi yang dimiliki dan dianggap bermanfaat bagi petani itu sendiri.

\section{Motivasi Petani}

Hasil analisis Koefisien Korelasi Rank Spearman antara variabel motivasi petani dan tingkat adopsi petani pada teknologi budidaya padi sawah sistem legowo sebesar 0,774 dengan probabilitas untuk uji dua pihak sebesar 0,000. Karena nilai probabilitas ini lebih kecil dari taraf nyata maka disimpulkan untuk menolak hipotesis nol, berarti terdapat hubungan yang nyata antara variabel motivasi petani dengan tingkat adopsi petani pada teknologi budidaya padi sawah sistem legowo. Dan ini signifikan pada taraf kepercayaan $95 \%$. Kenyataan di lapangan bahwa semakin tinggi tingkat motivasi petani maka akan semakin tinggi pula tingkat adopsi teknologi legowo yang mereka terapkan. Dengan motivasi yang tinggi untuk terus berusaha mendapatkan hasil yang lebih baik dari hasil-hasil panen sebelumnya dan melebihi hasil yang didapat oleh orang lain, maka petani itu akan menerapkan teknologi legowo dengan sebaik-baiknya, sesuai dengan apa yang dianjurkan. Hasil penelitian ini sesuai dengan hasil penelitian Komar (2005) yang menjelaskan bahwa terdapat hubungan yang nyata antara motivasi petani dengan adopsi teknologi legowo. Dijelaskan juga bahwa jika motivasi kerja petani meningkat, maka kecenderungan menerapkan teknologi legowo pada usahatani 
padi sawah akan meningkat pula. Namun hasil penelitian ini tidak sesuai dengan hasil penelitian Juita (2005), yang menjelaskan bahwa motivasi tidak berhubungan nyata dengan tingkat adopsi teknologi PTT. Dijelaskan juga bahwa petani yang motivasi kerjanya lebih tinggi tidak dapat dipastikan penerapan teknologi PTT akan lebih baik daripada petani yang tingkat motivasinya rendah.

\section{Aktivitas Petani Mengikuti Penyuluhan Pertanian}

Hasil analisis Koefisien Korelasi Rank Spearman antara variabel aktivitas petani mengikuti penyuluhan pertanian dan tingkat adopsi petani pada teknologi budidaya padi sawah sistem legowo sebesar 0,961 dengan probabilitas untuk uji dua pihak sebesar 0,000. Karena nilai probabilitas ini lebih kecil dari taraf nyata maka disimpulkan untuk menolak hipotesis nol, berarti terdapat hubungan yang nyata antara variabel aktivitas petani mengikuti pentuluhan pertanian dengan tingkat adopsi petani pada teknologi budidaya padi sawah sistem legowo. Dan ini signifikan pada taraf kepercayaan $95 \%$. Dengan kata lain jika aktivitas mengikuti penyuluhan pertanian seorang petani tinggi, maka kecenderungan menerapkan teknologi legowo juga akan tinggi, karena dalam kegiatan penyuluhan, hal-hal yang disampaikan adalah berupa aplikasi dari penggunaan masing-masing tahapan teknologi khususnya teknologi legowo. Sehingga dengan tingginya aktivitas mengikuti penyuluhan pertanian akan mempercepat pengadopsian teknologi legowo secara baik.

Selain itu penyebaran ide baru tidak tergantung pada media cetak maupun media elektronik, tetapi juga tergantung pada diskusi-diskusi secara langsung antara orang perorangan atau antar kelompok masyarakat. Sebagian besar tujuan petani aktif dalam kegiatan penyuluhan pertanian adalah untuk menambah pengetahuan dan keterampilan dalam usahataninya. Melalui penyuluhan, aspirasi petani dapat disampaikan dan dihimpun oleh petugas penyuluh. Dengan demikian, tingginya aktifitas 
petani dalam mengikuti penyuluhan pertanian akan memberikan kontribusi positif bagi penerapan inovasi teknologi pertanian (Soekartawi, 1988).

Hasil penelitian ini sesuai dengan pendapat Soekartawi (1988) bahwa pendidikan nonformal berupa penyuluhan pertanian dan pelatihan akan meningkatkan kwalitas petani dari segi keterampilan dan pengetahuan, sehingga dengan demikian makin tingginya aktifitas petani dalam mengikuti penyuluhan pertanian maka akan semakin cepat proses adopsi teknologi. Hal ini juga sesuai dengan pendapat Mulyani (2001) dijelaskan bahwa pendidikan nonformal berupa penyuluhan pertanian akan dapat mempercepat proses pengadopsian suatu inovasi baru.

\section{Persepsi Mengenai Teknologi Legowo}

Hasil analisis Koefisien Korelasi Rank Spearman antara variabel persepsi mengenai teknologi legowo dan tingkat adopsi petani pada teknologi budidaya padi sawah sistem legowo sebesar 0,914 dengan probabilitas untuk uji dua pihak sebesar 0,000. Karena nilai probabilitas ini lebih kecil dari taraf nyata maka disimpulkan untuk menolak hipotesis nol, berarti terdapat hubungan yang nyata antara variabel persepsi mengenai teknologi legowo dengan tingkat adopsi petani pada teknologi budidaya padi sawah sistem legowo. Dan ini signifikan pada taraf kepercayaan $95 \%$. Dengan demikian, hasil penelitian ini mendukung hipotesis penelitian yakni terdapat hubungan antara persepsi petani dengan tingkat adopsi teknologi budidaya padi sawah sistem legowo. Semakin baik persepsi petani terhadap teknologi legowo maka akan semakin tinggi pula tingkat adopsi teknologi legowo yang mereka terapakan.

\section{Kosmopolitnes Petani}

Hasil analisis Koefisien Korelasi Rank Spearman antara variabel kosmopolitnes petani dan tingkat adopsi petani pada teknologi budidaya padi sawah sistem legowo sebesar 0,022 dengan probabilitas untuk uji dua pihak sebesar 0,894 . 
Karena nilai probabilitas ini lebih besar dari taraf nyata maka disimpulkan untuk menerima hipotesis nol, berarti tidak terdapat hubungan yang nyata antara variabel umur dengan tingkat adopsi petani pada teknologi budidaya padi sawah sistem legowo. Dan ini tidak signifikan pada taraf kepercayaan 95\%. Artinya tinggi rendahnya tingkat kosmopotnes petani tidak akan Berhubungan pada tinggi rendahnya tingkat adopsi teknologi legowo. Tidak berhubungan nyata antara kosmopolitnes petani dengan tingkat adopsi teknologi legowo, karena pengetahuan tentang teknologi legowo tidak akan mereka dapatkan dengan tingginya tingkat mereka bepergian keluar daerah atau berinteraksi dengan orang lain diluar sistem sosialnya, kecuali mereka sengaja mencari informasi atau menanyakan tentang teknologi legowo itu sendiri. Hasil penelitian ini tidak sesuai dengan hasil penelitian Juita (2005) bahwa ada hubungan yang nyata antara tingkat kosmopolitan dengan tingkat adopsi teknologi PTT. Dijelaskan bahwa hal ini disebabkan keterbukaan petani terhadap berbagai sumber informasi pertanian menyebabkan semakin tinggi pula kemampuannya dalam mengkombinasikan data dan informasi yang diperoleh untuk memutuskan penerapan paket teknologi yang dianjurkan.

\section{KESIMPULAN DAN SARAN}

\section{Kesimpulan}

Berdasarkan hasil penelitian dan pembahasan yang telah dilakukan, maka dapat disimpulkan sebagai berikut :

1. Tingkat adopsi petani pada teknologi budidaya padi sawah sistem legowo di Kelurahan Dusun Besar Kecamatan Gading Cempaka Kota Bengkulu tergolong tinggi, dimana untuk kategori tinggi sebanyak 40 responden atau sebesar $100 \%$, untuk kategori sedang sebesar $0 \%$ atau tidak ada responden yang masuk dalam 
kategori sedang, serta untuk kategori rendah sebesar $0 \%$ atau tidak ada responden yang masuk dalam kategori rendah.

2. Faktor tingkat pendidikan formal, motivasi petani, aktivitas petani dalam penyuluhan pertanian, dan persepsi petani mengenai teknologi legowo berhubungan nyata dengan tingkat adopsi petani pada teknologi budidaya padi sawah sistem legowo. Sedangkan faktor umur, luas lahan, pengalaman berusahatani padi dan kosmopolisnes petani tidak berhubungan nyata dengan tingkat adopsi petani pada teknologi budidaya padi sawah sistem legowo.

\section{Saran}

Mengingat tingkat aktivitas petani dalam penyuluhan pertanian merupakan salah satu faktor yang sangat potensial untuk dapat meningkatkan adopsi teknologi budidaya padi sawah sistem legowo, maka diharapkan kepada petani untuk lebih meningkatkan aktifitasnya dalam penyuluhan pertanian baik yang diadakan oleh penyuluh pertanian maupun agen-agen pembaharu lainnya. Yang pada ahirnya dapat meningkatkan hasil produksi padi sawah serta berujung pada kesejahteraan petani.

\section{DAFTAR PUSTAKA}

Juita, E. 2005. Faktor-Faktor Penentu Tingkat Adopsi Teknologi Pengelolaan Tanaman dan Sumberdaya Terpadu (PTT) pada Usahatani Padi Sawah Di Desa Rimbo Kedui Kecamatan Seluma Selatan Kabupaten Seluma. Skripsi (S1) Jurusan Sosial Ekonomi Pertanian Fakultas Pertanian UNIB. Bengkulu.(tidak dipublikasikan)

Komar, S. 2005. Analisis Faktor-Faktor yang Berhubungan Dengan Adopsi Teknologi Legowo Pada Usahatani Padi Sawah Di Desa Penanjung Panjang Kecamatan Tebat Karai Kabupaten Kepahiang. . Skripsi (S1) Jurusan Sosial Ekonomi Pertanian Fakultas Pertanian UNIB. Bengkulu.(tidak dipublikasikan) 
Kusai. 1997. Tingkat Adopsi Petani Ikan Terhadap Teknologi Budidaya Ikan Dalam Keramba Terapung (Kasus di Kecamatan Bangkinang Barat Kabupaten Kampar Propinsi Riau). Jurnal Penelitian Universitas Riau, 1 (1) : 76-80. Fakultas Pertanian Universitas Riau.

Mardikanto, T. 1993. Penyuluhan Pembangunan Pertanian. Sebelas Maret University Press. Jakarta.

Mulyani, T. 2001. Faktor Penentu Tingkat Adopsi Teknologi Usahatani Jagung (Studi Kasus di Desa Riak Siabun Kec. Sukaraja Kab. Bengkulu Selatan). Skripsi (S1) Jurusan Sosial Ekonomi Pertanian Fakultas Pertanian UNIB. Bengkulu.(tidak dipublikasikan)

Nazir, M. 1988. Metode Penelitian. Ghalia Indonesia. Jakarta

Redfield, R. 1982. Masyarakat Petani dan Kebudayaannya. CV. Rajawali, Jakarta.

Sastrawan. 2000. Adopsi Usahatani Jeruk Di Kecamatan Seginim Kabupaten Bengkulu Selatan. Skripsi (S1) Jurusan Sosial Ekonomi Pertanian Fakultas Pertanian UNIB. Bengkulu.(tidak dipublikasikan)

Siegel, S. 1998. Statistik Non Parametrik. PT. Gramedia, Jakarta.

Soekartawi. 1988. Prinsip Dasar Komunikasi Pertanian. Universitas Indonesia Press, Jakarta

—. 1996. Pembangunan Pertanian Untuk Mengentaskan Kemiskinan. Universitas Indonesia, Jakarta.

Suminar,P. 1989. Faktor-Faktor yang Berpengaruh Terhadap Adopsi Inovasi Pertanian. Balai Penelitian UNIB, Bengkulu. 